PROBLEMS

OF EDUCATION

IN THE $21^{\text {st }}$ CENTURY

Volume 66, 2015

\title{
CHANGING EDUCATIONAL THEORY AND PRACTICE
}

\author{
Boris Aberšek \\ University of Maribor, Slovenia \\ E-mail: boris.abersek@um.si
}

How do we think, how do we learn, memorize and dream, how does pleasure come to be, where are the emotions hidden and how do we reach decisions? Cognitive science and neuroscience tries to answer such questions. It tackles the fields of the human mind in an interdisciplinary, even transdisciplinary way - by connecting discoveries from all the disciplines that could shed light on cognitive occurrences. Cognitive science brings together psychology, philosophy, linguistics, artificial intelligence, social sciences and many others. It tries to deal with mental processes in a holistic way and to create a deeper understanding of the field that is empirically closest to us.

In recent decades cognitive science has been experiencing rapid development. Because of advances in neuroscience, we are slowly starting to speculate that it may be possible to scientifically research mental occurrences and even consciousness - a field which was until recently reserved only for mystics. Cognitive scientists are trying to transfer their findings into practice - especially in the field of learning and teaching, processes of collaborative work and in the field of machine learning and decision making. Cognitive science developed from a movement of cybernetics in the 1950s and has since experienced numerous pragmatic changes. Study programs in cognitive science, which in the last twenty years have sprung up in all important universities worldwide, most often, have separate constitutive disciplines (for example, cognitive linguistics, cognitive neuroscience, cognitive anthropology, etc.). However, it is becoming increasingly evident that only an equal discussion of all fields can ensure a holistic discussion of mental occurrences and learning processes, and thus, of teaching (Aberšek, Borstner, Bregant, 2014).

Over the last decade many studies have been done in the field of education that have predicted crucial changes in educational systems. These include the following: Joint Research Center (2012), UNESCO (2008), Microsoft Partners in Learning (2010), OECD (2009) and OECD (2007). Other similar studies include PISA, UNESCO, EU commissions, PIRLS, ICILS, TAUS and HBSC. All this research shows that the area of education is undergoing drastic change, that it requires new paradigms and approaches to teaching, especially when introducing new technology.

It is evident that today's understanding of learning and teaching has reached maturity, and changes in the educational paradigm have become more and more necessary. For this reason, a new understanding of the educational system is needed which will facilitate merging and new divisions of teaching/learning disciplines. Under such a paradigm, the disciplines propel the evolution of knowledge, but will adapt when driving forces emerge that are sufficient to provoke their adaptation (Suarez-Orozco, Satin-Bajaj, 2010). In the case of neuroscience, cognitive science and education, a more comprehensive understanding of learning is a compelling driving force, since it is critical to broader goals, such as sustainable economic growth, societal cohesion and personal development (Hirsch Hadorn, et al., 2008). 


\section{New Paradigm - Cognitive Neuroeducation}

The current state of neuroscience, cognitive science and education provides a good illustration of the shortcomings of disciplinary separation (Aberšek, 2013), which must be overcome. In the field of learning, recent advances in neuroscience and cognitive science have produced powerful insights, while educational research has accumulated a substantial knowledge base (Aberšek, Borstner, Bregant, 2014, 2014b). A neuroscientific and cognitive perspective on learning adds a new, important dimension to the study of learning (and teaching) in education, and educational knowledge could help direct neuroscience and cognitive science research towards more relevant areas. Because all fields are well-developed, however, they have deeply-rooted disciplinary cultures with field-specific methods and language, which makes it extremely difficult for the experts from one field to use the knowledge in the other. Fusing neuroscience, cognitive science with education and other relevant disciplines, and creating a new trans-disciplinary field would connect work on learning across the intellectual walls dividing disciplines (Flogie, Dolenc, Aberšek, 2015) (Figure 1).

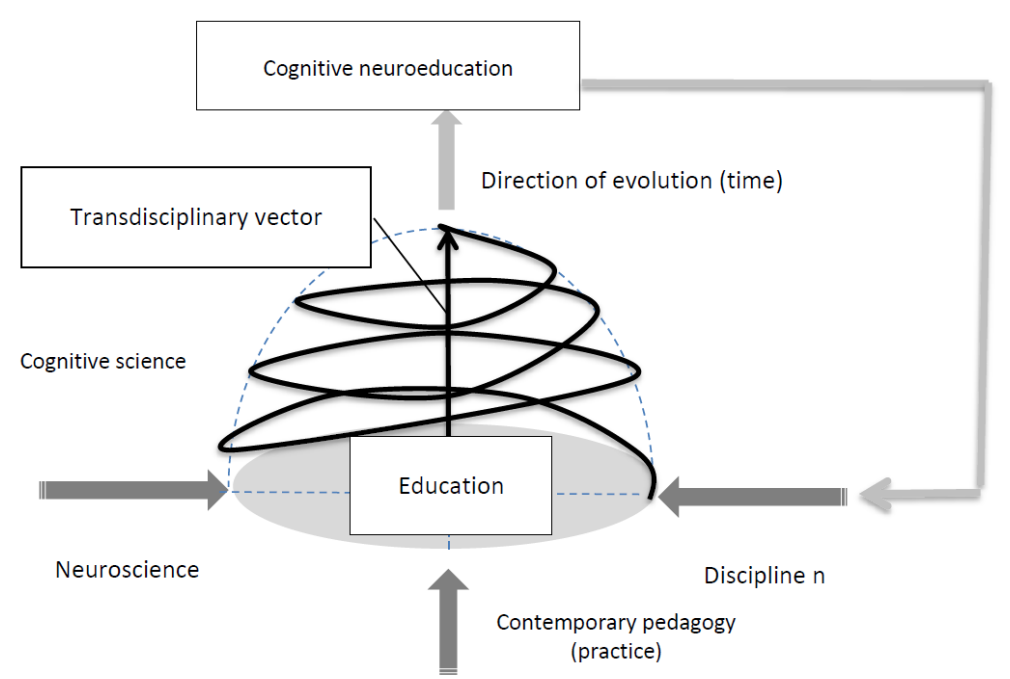

Figure 1: Birth of the new discipline: Cognitive neuroeducation.

Cognitive neuroeducation, the new paradigm of education is generating valuable new knowledge to inform educational policy and practice: On many questions, neuroscience builds on the conclusions of existing knowledge and everyday observation, but its important contribution is in enabling the move from correlation to causation - understanding the mechanisms behind familiar patterns - to help identify effective solutions. The transformation of the transdisciplinary cognitive neuroeducation model into practice will be a serious challenge.

If we focus on the idea before us, we can rightly assume that the explanation will often be different from notions that are generally true. We hope that in so doing, we will provoke a state of cognitive dissonance - intellectual unease, in the reader of this Journal and in many others, a result which will encourage them to update and internalize the theoretical assumptions imbibed during their own school years. In order for teachers to internalize these suggestions permanently, certain conditions and encouraging environments need to be created, along with new experiences of alternative teaching practices. Creating conditions for gaining these teacher experiences is the primary function and fundamental mission of policy in the field of education. This brings us back to the beginning, to philosophy, paradigmatic changes and different pedagogical strategies. 
Boris ABERŠEK. Changing educational theory and practice

PROBLEMS

OF EDUCATION

IN THE $21^{\text {st }}$ CENTURY

Volume 66, 2015

\section{References}

Aberšek, B. (2013). Cogito ergo sum homomachine? Journal of Baltic Science Education, 12 (3), 268-270.

Aberšek, B., Borstner, B., \& Bregant, J. (2014). The virtual science teacher as a hybrid system: Cognitive science hand in hand with cybernetic pedagogy. Journal of Baltic Science Education, 13 (1), 75-90.

Aberšek, B., Borstner, B., \& Bregant, J. (2014b). Virtual teacher, cognitive approach to e-learning material. Newcastle upon Tyne: Cambridge Scholars Publishing.

Flogie, A., Dolenc, K., Aberšek, B. (2015). Transdisciplinarity in education is near. In.: Lamanauskas, V., Šlekiene, V., Ragulienè, L. (Eds.), State-of-the-art and future perspectives. Proceedings of the 1st International Baltic Symposium on Science and Technology Education (BalticSTE2015). Šiauliai: Scientia Socialis Press.

Hirsch Hadorn, G., Hoffmann-Riem, H., Biber-Klemm, S., Grosenbacher-Mansuy, W., Joya, D., Pohl, C., Wiessmann, U., Zemp E. (2008). Handbook of transdisciplinary research. Zurich: Springer Science + Business Media B.V.

Joint Research Center (2012). Innovative learning: key elements for developing creative classrooms in Europe (report EUR $25446 \mathrm{EN})$.

Microsoft Partners in Learning (2010). Bringing a 1-to-1 Program to Life, a Handbook for Senior Secondary School Teachers. Microsoft Corporation.

OECD (2009). Creating effective teaching and learning environments: First results from TALIS. Paris: OECD Publishing.

OECD (2007). Understanding the brain: The birth of learning science. Paris: OECD Publishing.

Suarez-Orozco, M. M., Satin-Bajaj, C. (2010). Educating the whole child for the whole world. The Ross School Model and education for the global era. New York and London: New York University Press.

UNESCO (2008). Global monitoring report: Education for all by 2015, will we make it? (ED 2007/WS/55). Paris: United Nations Educational, Scientific and Cultural Organization.

Received: August 18, 2015

Accepted: August 25, 2015

Boris Aberšek

PhD., Professor, University of Maribor, Faculty of Natural Science and Mathematics, Koroška 160, 2000 Maribor, Slovenia.

E-mail: boris.abersek@um.si 